\title{
CONTINUIDAD Y CONFLICTOS INTERGENERACIONALES
}

Por: Licer Viveros

\section{INTRODUCCIÓN}

\section{a) La Continuidad}

El concepto de continuidad tiene especial importancia en el análisis sociológico, porque su presencia contribuye de manera decisiva al mantenimiento del orden social. En este contexto la continuidad tiene una doble connotación, que se observa en los conceptos de regularidad, equilibrio y recurrencia de los hechos sociales, lo cual, como sabemos, hace posible la existencia de la Sociología en tanto ciencia, cuya materia objeto aparece así como algo que admite anticipaciones predictivas en relación con los procesos de interacción social y sus resultados, que son de interés para esta disciplina científica.

Por lo demás, el concepto de continuidad implica una condición necesaria para la misma existencia de la sociedad, ya que no sería posible pensarla como un suceder discreto de acontecimientos, aun cuando en tal proceso puedan producirse cambios rápidos o paulatinos; ello es así porque algunas características básicas de los sistemas de acción operantes persisten y le confieren identidad a cualquiera sociedad. Piénsese, por ejemplo, en aquellas sociedades que en algún momento fueron sojuzgadas, todas ellas sin excepción conservaron aquellos rasgos que las hacian inconfundibles, es decir, la continuidad, a pesar de todo, ya sea que fueran dominadas militar o políticamente, no fue truncada en modo alguno en términos absolutos. Nadie diría que la sociedad alemana o japonesa perdió lo esencial de sus rasgos socioculturales luego de las derrotas bélicas, tampoco podemos desconocer lo que ha ocurrido con las sociedades y culturas originarias de América, cuyos pueblos, que casi fueron exterminados, aún conservan y, todavía más, se les protege para que mantengan la continuidad de sus identidades socioculturales. 
Es oportuno señalar ahora, en esta argumentación inicial, centrada de modo sucinto en una visión macrosocial, algunos elementos the carácter microsocial, focalizados en la familia, reconocida como la unidad básica y punto de partida para la incorporación de las cohortes de reemplazo a la vida de la sociedad. Como se sabe, es en ella donde tienen lugar las distintas etapas a través de las cuales se transmiten los valores y las normas, en suma la cultura de la sociedad; allí el ser humano llega a ser social con todas las diferencias cualitativas posibles de observar, según sea el marco referencial de sus potencialidades naturales o del grupo en el cual inicia su vida.

\section{b) El Conflicto}

En cuanto al conflicto, que sociológicamente se inscribe también entre los procesos de interacción social, digamos que su caracterización más elemental consiste en el enfrentamiento antagónico de dos o más personas que intentan conseguir algún objetivo respecto de los cuales se comparte un juicio evaluativo, sea como bien escaso, o como conducta apropiada. En general, los conflictos aparecen en la vida social a causa de que las recompensas, beneficios o gratificaciones, materiales o inmateriales, existen y se dan en cantidad relativamente limitada en la sociedad.

Una definición preliminar para el conflicto la encontramos en la obra de Lewis A. Coser Las funciones de/ Conflicto Social, quien en su prefacio postula de manera provisional que el conflicto es "una lucha respecto a valores y derechos sobre situaciones, poderes y recursos escasos, lucha en la cual el propósito es neutralizar, dañar o eliminar a los rivales*". En este mismo autor, que a lo largo de esta obra toma como epigrafes de referencia citas sucesivas de Georg Simmel, encontramos una distinción importante entre los llamados conflictos reales y conflictos irreales. El primero, esto es, conflicto real, se caracteriza porque el enfrentamiento, la lucha o la rivalidad constituyen medios para conseguir un fin o resultado específico. En tanto que, los conflictos irreales, aun cuando también interactúan dos o más personas, se caracterizan porque surgen de impulsos agresivos que buscan salida para liberar al menos la tensión de uno de los implicados. En este segundo caso la persona actúa, como dice el aforismo popular, haciendo que otros "paguen las habas".

Si recordamos al sociólogo alemán Georg Simmel** registramos cuatro tipos principales de conflictos: guerras entre grupos, rivalidades, litigios y conflictos por ideales no personalizados, siendo estos últimos los más destructivos e inmisericordes, llegando incluso a provocar cualquiera de los tres que se han mencionado

* Fondo de Cultura Económica. México, 1961, p. 8

* Conflict (traducción de Kurt H. Wolff) The Free Press. Glencoe, 111, 1955. 
primero. Algunos pensadores sociales afirman que el conflicto es un problema que proviene de una organización social defectuosa y que, por lo tanto, un sistema social perfecto, bien controlado por el consenso, por la fuerza, o por los intereses creados, no tendría conflictos; sin embargo, parece dificil imaginar interacciones sociales en las que todo lo deseable pudiera ser satisfecho sin involucrarse en esfuerzos o competencia por conseguirlo.

Sin duda, cuando pensamos en la significación social del conflicto tendemos con mayor probabilidad a percatarnos o a enfatizar sus aspectos negativos, sin embargo, diversos sociólogos siguiendo el pensamiento de Simmel, registran algunos aspectos positivos $y$, autores como Coser, llegan al extremo de afirmar que si la sociedad tuviera éxito en eliminarlos, tal estado social no sería deseable, porque la vida humana carecería de ese potenciador dinámico que agudice el interés y el deseo de logro. Además, según este autor el conflicto puede servir como una fuerza que integra a los grupos que se enfrentan, es decir, mirado desde las teorías de los grupos, el grupo interior, el grupo de pertenencia reforzaría sus nexos y, contribuiría a la unidad, integración y reforzamiento de la identidad con lo cual vendría, como un efecto no buscado originalmente, a intensificarse la identidad y consecuencialmente la continuidad de las características socioculturales del grupo.

Por último, los grupos que alcanzaran este nivel del conflicto en algún momento han de llegar a la necesidad de buscar mecanismos de arbitraje o de comunicación entre ellos a fin de encontrar procedimientos que les permitan enfrentar y resolver la situación problemática del conflicto.

\section{LA SITUACIÓN A NIVEL INTERGENERACIONAL}

Para los propósitos de esta exposición el concepto de generación se refiere a la posición relativa de un individuo con respecto a otros, particularmente teniendo presente las líneas biológicas de ascendencia y descendencia. Así, los padres pertenecen a la generación anterior, son los mayores con respecto a sus hijos y éstos forman la nueva generación, la generación joven. Por cierto ambas generaciones comparten con sus pares muchas características, entra otras evidentemente aquellas de la edad, del estado civil, y de sus relaciones de dependencia o independencia. Como es natural esas características y otras pueden ser lisa y llanamente aceptadas, otras en cambio, constituyen fuentes de conflictos a los cuales nos referiremos a continuación.

Llevado el análisis a las condiciones de la vida familiar debemos remitirnos a un concepto habitualmente caracterizado por su calidez, nos referimos al concepto de hogar, es decir, al conjunto de componentes materiales e inmateriales donde ocurre la vida de la familia. Hemos de admitir la existencia de variadas clases de hogares, unos pueden llegar a ser calificados como aquéllos donde todo se cumple 
en un nivel ideal, otros, en el extremo opuesto, como el lugar más indeseable donde se tenga que vivir. Algunos hogares tienen un marco físico muy restringido, otros pueden alcanzar gran amplitud. Recordemos para el caso algunos párrafos de Huxley en su novela "Un Mundo Feliz":

"Hogar, hogar... Unos pocos cuartitos, superpoblados por un hombre, una mujer periódicamente embarazada, y una turbamulta de niños y niñas de todas las edades. Sin aire, sin espacio; una prisión no esterilizada; oscuridad, enfermedades y malos olores".

"Yel hogar era tan mezquino psíquicamente como físicamente. Psíquicamente, era una conejera, un estercolero, lleno de fricciones a causa de la vida en común, hediondo a fuerza de emociones. ¡Cuántas intimidades asfixiantes, cuán peligrosas, insanas y obscenas relaciones entre los miembros del grupo familiar! Como una maniática, la madre se preocupaba constantemente por los hijos (sus hijos...), se preocupaba por ellos como una gata por sus pequeños; pero como una gata que supiera hablar, una gata que supiera decir: 'Nene mío, nene mío' una y otra vez. 'Nene mío, $y$, joh, oh, en mi pecho, sus manitas, su hambre, y ese placer mortal e indecible! Hasta que al fin mi niño duerme, mi niño se ha dormido con una gota de blanca leche en la comisura de su boca. Mi hijito duerme'...".

"Y sin embargo, entre los salvajes de Samoa, en ciertas islas de la costa de Nueva Guinea...

El sol tropical relucía como miel caliente sobre los cuerpos desnudos de los chiquillos que retozaban promiscuamente entre las flores de hibisco. El hogar estaba en cualquiera de las veinte casas con tejado de hojas de palmera. En las Trobiand, la concepción era obra de los espíritus ancestrales; nadie había oído hablar jamás de 'padre'.

- Los extremos se tocan- dijo el interventor. Por la sencilla razón de que fueron creados para tocarse".

En seguida, el modo como cada uno concibe su hogar está habitualmente cargado de connotaciones emocionales, en particular, cuando hacemos recuerdos o cuando estamos lejos. Si analizamos las características psicosociales de la vida hogareña nos encontraremos, por ejemplo, con distintos grados de unión real o aparente, puede haber casos en que tras una apariencia de gran unidad existan divisiones secretas, profundas, no explícitas... las razones para estas dualidades de sentimientos, aunque son bastante complejas pueden abreviarse con referencia a las dos dimensiones siguientes que se dan de modo conjunto: el amor surge de las interacciones positivas de interdependencia afectiva entre padres e hijos, mientras que las discordias y los antagonismos emanan de la pugna de dos generaciones, primero por el poder y la supremacía y luego, por el deseo de autorrealización.

Para sistematizar lo que acabamos de exponer, vamos a tratar de plantear algunas ideas acerca de lo que ocurre en los ciclos vitales desde que nacemos hasta que nos convertimos en adultos maduros y "autónomos". 
Al nacer la primera interacción entre la madre y ef hijo se limita esencialmente al contacto sensorial, que incluye el aprendizaje simple de mecanismos y gestos simbólicos no específicos. La madre es una fuente de nutrición y otros estímulos de acomodación, su conducta refuerza o refleja los estímulos agradables que asocia el niño, e influyen sobre él como recompensas o castigos simbólicos. Lo mismo ocurre con las palabras emocionalmente entonadas que, aun cuando no tengan referentes específicos, adquieren significados para configurar actitudes en el niño y desarrollar una concepción de sí mismo.

Al respecto, desde las tragedias griegas hasta el psicoanálisis moderno se ha podido constatar que como un paralelo a la visión romántica de los sentimientos familiares, la familia y el hogar son también un lugar de rivalidades y conflictos donde tanto las lesiones psíquicas como las físicas suelen aparecer. El psicoanalista R. Laing ha afirmado que "el primer acto inicial de brutalidad en contra del promedio de los niños es el primer beso de la madre". Este psicoanalista encuentra dañino que un niño esté completamente a merced de los adultos aun para tener que aceptar las manifestaciones de afecto de sus padres, y qué decir de aquellas que se consideran como de necesidad obligada por parte de parientes $u$ otras personas al ver a un recién nacido, donde no es raro encontrar gestos de hipocresía o envidias y agresividad encubiertas; ¿punto de partida del conflicto intergeneracional?...

Con el crecimiento los procesos de aprendizaje aumentan, haciéndose progresivamente más complejos, pudiendo las distinciones entre lo correcto y lo incorrecto llegar a ser definidas de manera inconsistente. La internalización de valores $y$ normas se convierte en la atmósfera donde se evalúan las recompensas o los castigos; así hay comportamientos que pueden ser aceptados o rechazados según la evaluación y el prestigio que se les confiera. Poco a poco van decantándose las manifestaciones de conducta que merecen aceptación; pero, por otra parte, van también surgiendo los deseos de ensayar maneras propias de vivir o percibir las situaciones y de conferirle su carácter valente.

A ninguno de nosotros escapa que el ejercicio del poder es implícitamente placentero. Para muchas personas sólo es posible ejercerlo sobre sus propios hijos. Pudiera ser que para el niño sea bueno obedecer, pero no siempre podemos garantizar que la sabiduría de los padres amerite tal obediencia y, además, podemos estar seguros que muchos padres son renuentes a entregar el tributo a su poder y sabiduría. Sin embargo, en nuestra época parece haber llegado el tiempo en que la autoridad de los padres, es decir, su derecho al poder, está siendo cuestionado seriamente cuando la rebelión abierta no se ha ya manifestado, porque en los hechos, a medida que un niño crece, va enfrentando críticamente a sus mayores, a veces de manera desafiante encubierta o manifiesta y ocurre, lamentsblemente, que muchos de los que se ven enfrentados a esta inspección analítica no resisten la agudeza del examen.

El celebrado, aunque a veces poco conocido, escritor checoslovaco Franz Kafka 
en dos cartas que escribió sobre la educación de los niños, nos ofrece un visión muy particular, pero representativa acerca del tema que nos preocupa. Dice él: "la ternura con respecto a los hijos deriva de las mismas leyes naturales que unen a hombres y mujeres en sus contactos amorosos, donde no son escasas las bajezas y miserias de la condición humana y en que el egoísmo por la posesión del otro se enraíza en el principio de las relaciones animales". La familia representa en la versión kafkiana ese tipo de relaciones, de tal manera, lo afirma "de entre todos los seres humanos, es a los padres a quienes menos debe confiárseles la educación de los hijos". Según él se produciría una especie de incesto espiritual. Recordemos, que Kafka está siguiendo a Swift en su descripción del viaje de Gulliver a Liliput, donde la familia es concebida como un organismo complicado y desequilibrado que aspira al equilibrio, aspiración que entre padres e hijos habria de producirse a través de lo que se llama educación que, hasta donde Kafka lo entiende, no tiene nada "del desarrollo sereno, desinteresado y afectuoso de las aptitudes de un hombre en su evolución, o siquiera de la tolerancia tranquila de un desarrollo independiente". En este esquema los hijos estarían condenados a muchos años de desequilibrio a causa de la enorme supremacía del poder de los padres que, por largo tiempo, poco a poco "les quitan" su derecho a la personalidad propia y pueden llegar a anularles la capacidad de desarrollar positivamente este derecho; ello es una desgracia que, con el tiempo, puede tocar no menos a los padres que a los hijos.

Kafka agrega que el egoísmo como sentimiento paterno no reconoce límites, los padres no son libres frente a sus hijos porque cuando los educan encuentran en ellos aspectos que ya han odiado en si mismos y que no pudieron superar. De tal manera, a partir de ese egoísmo aparecen formas de tirania y esclavitud que de manera muy suave y graduada se expresan en frases como "idebes creerme pues soy tu padre!", "itú eres mi hijo, por eso te convertiré en mi salvador". Estos son modos de amor irracional que de ninguna manera constituyen educación, a lo más podrían aplastar o en el mejor de los casos desencadenar los conflictos.

Esto que hemos expuesto a través de la cita de Kafka no tiene como telón de fondo la existencia de relaciones maritales perturbadas, se trata de la relación normal de una pareja sin problemas. Ya está claro que los padres ejercen influencia sobre el desarrollo de la personalidad de sus hijos, la cual se ve mayormente alterada si los patrones de interacción al interior de la familia ocurren en un marco en que la pareja está mal relacionada. En estos casos suele ocurrir que los conflictos de relaciones entre los padres se desplazan hacia los hijos convirtiendo a éstos en "el chivo expiatorio" para sus propios problemas, por ejemplo, una mujer que siente hostilidad hacia su marido porque el rendimiento de éste en su trabajo es insuficiente, canaliza su hostilidad hacia el hijo por su bajo rendimiento escolar. El padre la acompaña en sus críticas y desvía la atención de su mujer hacia el hijo en lugar de examinarse a sí mismo, de esta manera convierten al hijo en un mecanis- 
mo psicosocial de escape, en un "chivo expiatorio", estos hechos lo forzarian a implicarse en un rol perturbado en que la sumisión o la rebeldía pueden ser las consecuencias, pues sabemos que las expectativas de los padres son extremadamente importantes para definir el rol que desempeñe el niño y la autoimagen que éste desarrolle. Si personas importantes para él no le entregan su confianza fácilmente puede llegar a desconfiar de sí mismo.

Una segunda etapa importante la constituye la adolescencia, a decir de Piaget, crisis pasajera que separa la infancia de la edad adulta, en la que a pesar de su transitoriedad se desarrollan, además de los cambios fisiológicos, importantísimas modificaciones en el campo de las ideas y de la conducta social. Entre otros aspectos importantes puede señalarse también una manifiesta resistencia a la autoridad paterna, el adolescente se vuelve tan capaz de razonar como sus padres, y a menudo, puede ganar una discusión. De hecho, en muchas materias el adolescente puede estar razonablemente bien informado, principalmente porque una parte importante de su tiempo transcurre fuera del marco familiar y ya no puede ser fácilmente supervisado. Físicamente dispone de una mayor cantidad de energía y habilidad para recobrarse de la que gozan sus padres, y los impulsos y tensiones internos que lo caracterizan lo llevan a buscar sus propias metas con gran tenacidad. El conflicto con sus padres, que puede acrecentarse con la juventud, estará relacionado con asuntos filosóficos y políticos, aparte de que cada día adquirirá valores, actitudes y preferencias diferentes tanto con respecto a la vida presente como al futuro que le espera. En las sociedades tradicionales tales fenómenos eran menos posibles de ocurrir porque la continuidad y la persistencia eran el rasgo cultural predominante. Esta situación, de hecho, no ocurre hoy día, los rápidos cambios sociales van socavando y haciendo irrelevantes las orientaciones filosóficas, políticas o valóricas de los padres, con lo cual a los adolescentes les parece urgente apartarse de ellas o, por lo menos, intentar aislarse del control de sus padres para crear una vida social independiente que les garantice su autonomia.

Parece evidente, a partir de lo recién expuesto, que la hostilidad y las tensiones configuran aspectos que contribuyen a la explicación o a la comprensión de los antagonismos propios del conflicto, puesto que en todo conflicto siempre se constata una interacción entre dos o más personas.

En el caso de las interacciones conflictivas en la familia, las fuentes para la hostilidad y las tensiones pueden ser de la más diversa índole. Entre otras, se pueden mencionar la envidia, los resentimientos, los sentimientos de inferioridad, las incompatibilidades en cuanto a las expectativas, el modo como se comprende la autoridad y la permisividad, la tendencia a expresarse de modo intransigente, la competitividad, etc.

Para ilustrar pensemos, por ejemplo, en las preferencias respecto al sexo de los hijos, en el orden del nacimiento y ciertos favoritismos, en la importancia atribuida a la primogenitura, en las comparaciones referidas a características de los hijos 
alabando o ridiculizando a alguno de ellos, en la imposición de exigencias por sobre las potencialidades, en las referencias a modelos extraños o ajenos supuestamente dignos de ser imitados, etc.

Para nuestro intento de analizar el conflicto intergeneracional al interior de la familia, además de las variables psicoanalíticas, culturales y de aquellas provenientes de la interacción, es necesario incorporar también una de carácter estructural referida a la cohesión del grupo, aspecto que se hace más comprensible en el ejemplo de cotejar cualitativamente el desempeño de quienes sirven una causa como voluntarios contrastado con el de aquellos calificados como mercenarios. Sin duda en los primeros observamos un mayor involucramiento afectivo y motivacional, su participación será más integral, es decir, con toda su personalidad. Esta proposición la analizaremos más adelante.

Retomemos ahora las manifestaciones de hostilidad que ocurren en las relaciones sociales de carácter más íntimo. Ya sabemos que los antagonismos rara vez están ausentes al interior de los grupos. Allí las relaciones sociales incluyen motivaciones que pueden simultáneamente inscribirse en las motivaciones del amor y del odio. De nuevo la sabiduría popular nos ayuda en la comprensión de estas materias "del odio al amor no hay más que un paso" o "quien te quiere, te aporrea". Sin embargo, debemos entender que el odio no es una condición necesaria para todos los conflictos, sólo hemos de aceptarlo como uno de los componentes del conflicto en las relaciones más estrechas o intimas como son las del grupo primario que se concretiza en la familia. La sugerencia en este caso es que cuando se participa con todos los atributos integradores de la personalidad es más probable que aparezcan manifestaciones de atracción y hostilidad, de amor y odio. En estas ideas hay un componente freudiano expresado en la palabra ambivalencia, es decir, la presencia en una misma persona de sentimientos opuestos en su relación con otra.

Si aceptamos que los antagonismos y los conflictos son integrantes de la estructura del grupo, podemos también reconocer que en las relaciones afectivas de la vida familiar existe como un residuo de sentimientos hostiles que se encubre o desaparece con mecanismos de represión, aun cuando privadamente se pueda murmurar o protestar con expresiones que no se dicen en público. Estas formas de ambivalencia afectiva ocurren con mayor frecuencia en los grupos primarios donde la interacción es cara a cara, intima y duradera. Así, a medida que las relaciones son más estrechas, mayor es el involucramiento afectivo y mayor también la tendencia a no expresar los sentimientos hostiles, con lo cual probablemente se producirá una acumulación de hostilidad. A este respecto el antropólogo Malinowski en su análisis de la guerra* nos dice que "cuanto más reducido es el grupo..., cuanto más unido se halla por ciertos intereses comunes y por la convi-

* Malinowski. Bronislaw. Magic, Science and Religion. The Free Press. Glencoe, Illinois, 1948. 
vencia cotidiana, es más fácil que los integrantes se irriten y encolericen mutuamente", en sus palabras "la agresión, como la caridad, comienza por casa".

El razonamiento que venimos siguiendo nos conduce a exponer la siguiente proposición: "a mayor intimidad de la relación, mayor intensidad del conflicto"**.

En un grupo de personas afines y con características comunes y con un mayor compromiso de pertenencia, cualquiera diferencia tendería a expandirse de modo inesperado porque, en general, cuando se comparten características en común es probable que las personas tengan conceptos equivocados unas de otras, ya que tendemos a ser menos objetivos que cuando nos enfrentamos con extraños. Si a estos hechos se agregan las relaciones en que los participantes han debido reprimir sentimientos hostiles, habrá una acumulación que hará más intenso el conflicto cuando éste aparezca.

Cuando se analiza el odio social conectado al sentimiento colectivo de pertenencia, podemos llegar a imaginar que la nueva generación presenta una imagen similar a la de los renegados o los apóstatas. Un adolescente o un joven empeñado voluntaria o involuntariamente en la búsqueda de su propia identidad para sentirse autorrealizado como persona, habitualmente habrá de vulnerar con su conducta las expectativas usuales de su grupo familiar, aun aquellas que en el mejor de los casos reflejen las aspiraciones positivas que sus padres quisieran para él. Si sucede que la frecuencia de la interacción es alta, mayores serán en tal caso las oportunidades para que surjan manifestaciones de hostilidad reciproca y por tanto de posible conflicto.

Como venimos afirmando, el conflicto es parte de todas las relaciones sociales y comporta matices positivos en tanto conduce a la armonía y a la unidad del grupo. Este argumento parece una contradicción; sin embargo, si el conflicto contribuye a liberar las tensiones, adquiere un valor armonizador cuando los antagonistas se desahogan.

Por otro lado, la ausencia de conflictos no es en modo alguno un índice de estabilidad para el grupo, puesto que si se teme su ocurrencia ello obedecerá a que los nexos integradores del grupo son incapaces de aceptarlos y soportarlos, con lo cual se producirá una represión o un desplazamiento. En otras palabras, si las relaciones al interior de un grupo social son estables y sólidas, no habrá conflicto que las ponga en peligro, y por lo tanto, no se acumulará la hostilidad que haría surgir un conflicto mayor. El hecho de que existan conflictos puede ser un indicador de que los integrantes de la familia no evitan la expresión de sus hostilidades, pero a la vez, no temen que tal conducta deteriore sus relaciones.

Lamentablemente, si se analizan las exigencias que la sociedad está imponien-

* Coser, Op. cit. 
do a las generaciones nuevas, constatamos que, para ser socialmente competente, son cada vez mayores. El tiempo de socialización formal, de prepararse para una integración sin problemas es cada vez más largo y la moratoria para superarla cada vez más prolongada, con lo que puede -en los casos extremos-dar origen a una forma original de parasitismo social, fuente de nuevos conflictos porque se contraponen los anhelos de independencia personal con la difícil realidad de dependencia económica. Las expectativas cifradas por los padres, para las cuales habitualmente se hacen ingentes sacrificios que significan desgaste o deterioro de la energía vital y postergación de las propias gratificaciones, pueden crear un estado de frustración, puesto que los medios utilizados, en este caso esfuerzo y a veces privaciones, tardan con exceso en dar el fruto esperado. Piénsese por ejemplo, en las esperanzas paternas cuando el hijo estudia una carrera de larga duración y a cuyo término las posibilidades ocupacionales son escasas o insatisfactoriamente remunerativas; además, como sabemos las profesiones demandan cada vez una formación más completa, sea por los desarrollos provenientes de la tecnología o porque las especializaciones exigen formación agregada. Las vidas tanto de los progenitores como de los jóvenes profesionales han de encontrarse de pronto en una especie de situación sin salida que frustra y origina conflictos. 